\title{
Effectiveness of Plant Growth Regulators under Photoselective Greenhouse Covers
}

\author{
Anuradha Tatineni, ${ }^{1}$ Nihal C. Rajapakse, ${ }^{2}$ R. Thomas Fernandez, ${ }^{3}$ and James R. Rieck ${ }^{4}$ \\ Department of Horticulture, Clemson University, Clemson, SC 29634-0375
}

ADDITIONAL INDEX wORDs. Dendranthema $\times$ grandiflora, light quality, photomorphogenesis, plant growth regulation, R:FR, spectral filters

\begin{abstract}
Responses to selected chemical growth retardants (daminozide, paclobutrazol, and prohexadione-Ca) and $\mathbf{G A}_{1}$ and $\mathrm{GA}_{3}$ under photoselective greenhouse covers with various phytochrome photoequilibrium estimates $\left(\phi_{\mathrm{e}}\right)$ were evaluated using 'Bright Golden Anne' chrysanthemum [Dendranthema × Xmorifolium Ramat.)] as the model plant to better understand the height control mechanism by far red (FR) light depleted environments. Plant height linearly decreased as $\phi_{\mathrm{e}}$ increased from 0.72 to 0.83 . The rate of height decrease of daminozide treated plants was less than that of water (control) or $\mathbf{G A}_{3}$-treated plants. The rate of height reduction was not different between control and $\mathbf{G A}_{3}$-treated plants among chambers with various $\phi_{\mathrm{e}}$. Both paclobutrazol and prohexadione-Ca reduced plant height regardless of $\phi_{e}$, but the height reduction by paclobutrazol was more than that by prohexadioneCa. The combination of paclobutrazol and prohexadione-Ca reduced plant height more than either alone. $\mathrm{GA}_{1}$ reversed the height reduction caused by paclobutrazol and prohexadione-Ca regardless of $\phi_{e}$, but the height increase by $\mathrm{GA}_{1}$ was more when it was applied with prohexadione-Ca than when applied alone. Results show that photoselective covers with high $\phi_{\mathrm{e}}$ were effective in controlling height of chrysanthemums without chemical growth retardants. The linear relationship between plant height and $\phi_{e}$ suggests that effectiveness of photoselective covers increased as $\phi_{e}$ increased. The photosynthetic photon flux (PPF) transmission of photoselective covers decreased as the $\phi_{\mathrm{e}}$ increased because of the increasing dye concentration. Identifying photoselective covers that effectively filter out FR light from sunlight and reduce plant height while minimizing the PPF reduction is critical for commercial success of photoselective covers. Gibberellins are, at least partially, involved in height control by photoselective covers. Photoselective greenhouse covers did not reduce responsiveness to gibberellins, and it appears that the mechanism may be to suppress gibberellin biosynthesis. Results also suggest that increased metabolism of $\mathrm{GA}_{1}$ to $\mathrm{GA}_{8}$ was not the mechanism of height control by photoselective covers. Chemical names used: butanedioic acid mono (2,2-dimethylhydrazide) [daminozide]; $( \pm)-\left(\mathbf{R}^{*}, \mathbf{R}^{*}\right)-$ b-((4-chlorophenyl)methyl)-a-(1,1- dimethylethyl)-1H-1,2,4-triazole-1-ethanol [paclobutrazol]; 3,5-dioxo-4-(1oxopropyl)cyclohexanecarboxylic acid [prohexadione-Ca]; gibberellic acid [GA].
\end{abstract}

In the greenhouse industry, growers often place plants at close spacing on benches and produce hanging baskets in the space above benches to maximize space utilization. In addition to a reduction in photosynthetic photon flux (PPF), close spacing and overhead crops can increase the proportion of far-red (FR) light in the lower canopy due to the absorption of red (R) light by the upper canopy. This relative increase in FR light can result in tall and spindly plants. In commercial operations, undesirable extension growth is controlled by application of chemical growth retardants. Because of potential health risks to workers and consumers, use of growth regulating chemicals has been restricted on certain crops. For example, use of daminozide (Alar; Uniroyal Chemical Co., Middlebury, Conn.) has been banned in the United States for use in controlling vegetable transplant height. As a result, no chemical growth regulators are currently labeled for height control of vegetable transplants. Although chemical growth regulators are not banned, the ornamentals industry is also faced with strict regulatory measures regarding chemical usage. Therefore, both the vegetable and ornamentals

Received for publication 20 Dec. 1999. Accepted for publication 29 July 2000 South Carolina Agricultural Experiment Station technical contribution 4610. The Ornamental Enhancement research Program of the South Carolina Experiment Station and Mitsui Chemicals Inc., Tokyo, Japan, are gratefully acknowledged for financial support. The cost of publishing this paper was defrayed in part by the payment of page charges. Under postal regulations, this paper therefore must be hereby marked advertisement solely to indicate this fact.

${ }^{1}$ Graduate research assistant.

${ }^{2}$ Corresponding author; nrjpks@ clemson.edu.

${ }^{3}$ Current address: Department of Horticulture, Michigan State University, East Lansing, MI 48824-1325.

${ }^{4}$ Department of Experimental Statistics. industries could benefit from nonchemical alternatives for height control.

Plants are capable of detecting subtle changes in relative amounts of $\mathrm{R}$ and FR light in their environment and make morphological changes through phytochrome regulation. Upon prolonged exposure to a given environment, a photoequilibrium $(\phi)$ develops between the active phytochrome (Pfr) and the total phytochrome (Ptotal) $[\phi=$ Pfr:Ptotal ratio]. Morgan and Smith $(1976,1979)$ reported that stem elongation rate and height of a range of herbaceous plants were inversely proportional to the established $\phi$ in vivo. By creating an environment that promotes establishment of high $\phi$ in vivo, height of greenhouse crops can be controlled with no or minimal use of chemical growth retardants (Rajapakse and Kelly, 1992).

Environments rich in R relative to FR light are favorable for establishing a high $\phi$ in plants and methods to estimate the $\phi\left(\phi_{\mathrm{e}}\right)$ from radiation measurements have been described (Hayward, 1984; Sager et al., 1988). In collaboration with Mitsui Chemicals Inc. (Tokyo, Japan) we have developed experimental photoselective greenhouse covers with a dye that absorbs FR light. Light transmitted through these covers has a higher R:FR ratio and $\phi_{\mathrm{e}}$ than sunlight or the light transmitted through clear covers. The FR light absorption by photoselective covers increases as the dye concentration increases. By changing the dye concentration, we are able to generate photoselective covers with a range of $\phi_{\mathrm{e}}$. Preliminary trials indicate that these covers are effective in controlling height of a wide range of herbaceous plants without using chemical growth retardants and that height reduction increases as the $\phi_{\mathrm{e}}$ increases (Rajapakse et al., 1998). With the commercial development of photoselective greenhouse 

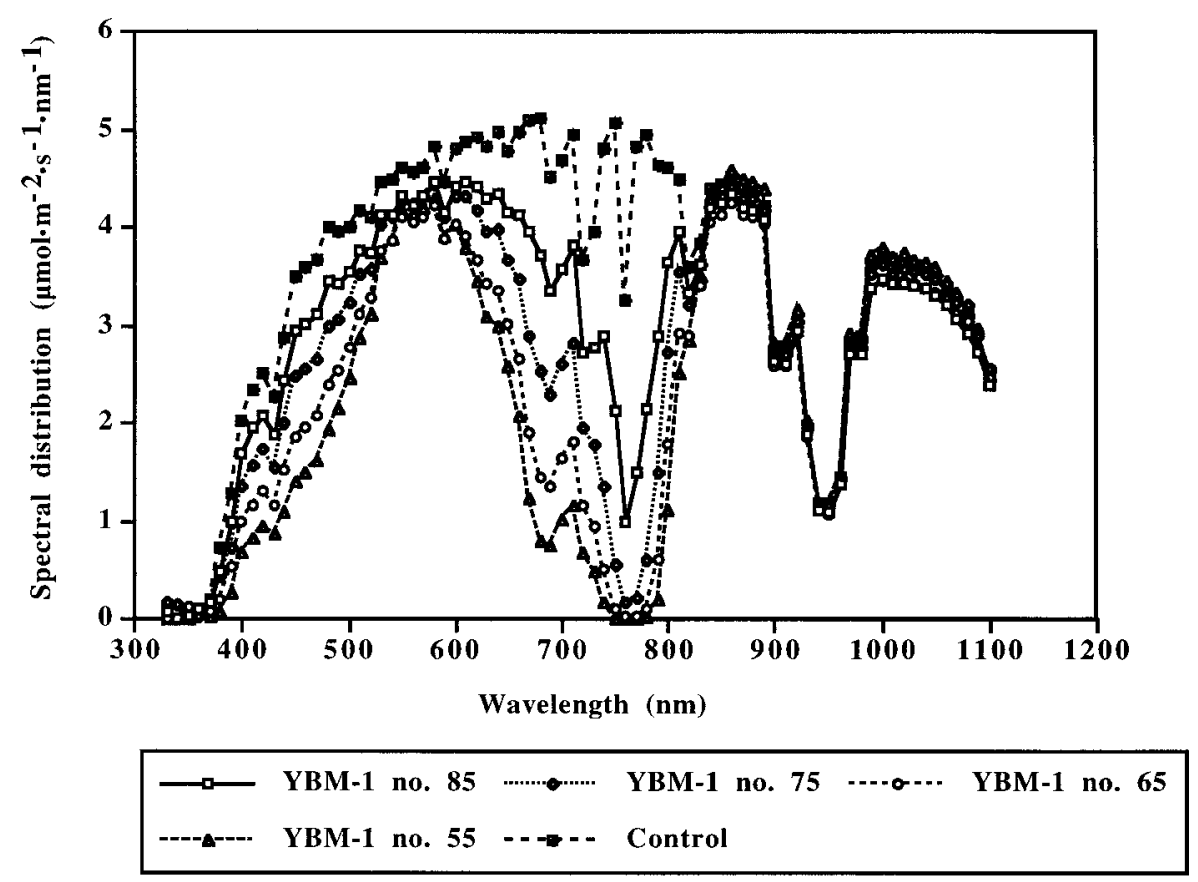

above PMMA panels. Each growth chamber had two fans on opposite sides, airflow oriented in the same direction, for ventilation. All growth chambers were inside a glass greenhouse.

PPF inside all chambers was adjusted to be the same by covering the chambers with higher PPF transmission with neutral density filters (shade cloth or cheesecloth), which did not alter light quality inside the chambers. Daily PPF integral inside the glasshouse was recorded with a data logger (LI1000) fitted with a quantum sensor (LI190SB) (both LI-COR, Lincoln, Nebr.).

Spectral photon flux distribution was determined at the beginning and end of the experiment in $10 \mathrm{~nm}$ increments from 330 to $1100 \mathrm{~nm}$ using a spectroradiometer (LI1800) fitted with a remote cosine sensor (LI1800-10) (both LI-COR) between 1200 and $1300 \mathrm{HR}$ on clear days. Spectral distribution curves of light transmitted through nonshaded photoselective covers are illustrated in Fig. 1. The dye in YBM-1

Fig. 1. Photon flux distribution of light transmitted through nonshaded photoselective panels containing various concentrations of FR light absorbing dye. Control is clear plastic panels without dye. Number following by YBM-1 indicates the percentage transmission of photosynthetic photon flux. Control, YBM-1 no. 85 , no. 75 , no. 65 , and no. 55 are chambers with $\phi_{\mathrm{e}}$ of $0.72,0.75,0.78$, 0.81 , and 0.83 , respectively.

covers or shade materials in the future, the greenhouse industry could reduce use of growth regulating chemicals, reduce health risks to their workers and consumers, and reduce potential environmental pollution. Although photoselective films are effective in regulating plant height, the mechanisms by which these films control stem elongation is not known. Understanding the mechanisms by which photoselective covers regulate stem elongation could be helpful in developing management strategies. The objectives of this research were to determine the response of plants grown under photoselective greenhouse covers with various $\phi_{\mathrm{e}}$ to $\mathrm{GA}_{1}$ and $\mathrm{GA}_{3}$ and gibberellin inhibitors to better understand height control mechanisms by photoselective covers.

\section{Materials and Methods}

Plant material. Rooted stem cuttings of 'Bright Golden Anne' chrysanthemum, (Yoder Bros. Inc., Pendleton, S.C.) were planted individually in $0.4-\mathrm{L}$ square plastic pots containing a commercial growing medium (Scotts Metro Mix-360, ScottsSierra Horticultural Products Co., Marysville, Ohio). Plants were grown inside a glass greenhouse for 1 week before initiation of treatments.

Рнотoselective covers. Polymethyl methacylate (PMMA) panels $(2.5 \mathrm{~mm}$ thick) with various concentrations of a FR absorbing dye were produced by Mitsui Chemicals, Inc. These PMMA panels are identified as control, YBM-1 no. 85, YBM-1 no. 75, YBM-1 no. 65, and YBM-1 no. 55. The percentages of PPF transmission by control, YBM-1 no. 85 , no. 75 , no. 65 , and no. 55 were $\approx 92 \%, 85 \%, 75 \%, 65 \%$, and $55 \%$, respectively. Five growth chambers $(1 \mathrm{~m}$ long $\times 0.8 \mathrm{~m}$ wide $\times 0.8 \mathrm{~m}$ high $)$ framed with polyvinyl chloride pipes were covered (all sides except the bottom which was white plastic) with each of the photoselective covers intercepted FR wavelengths of sunlight (maximum interception at $760 \mathrm{~nm}$ ). The interception of FR wavelengths increased as the dye concentration increased. Multiple light scan readings indicated that light quality was uniform within a chamber and did not change during the course of the experiment. The R:FR ratios ( $R=600$ to $700 \mathrm{~nm} ; \mathrm{FR}=700$ to 800 $\mathrm{nm})$ under the control, YBM-1 no. 85 , no. 75 , no. 65 , and no. 55 chambers were $1.1,1.5,2.7,4.3$, and 6.1 , respectively, and $\phi_{\mathrm{e}}$ [estimated as described by Sagar et al. (1988)] was 0.72, 0.75, $0.78,0.80$, and 0.83 , respectively (Table 1 ).

EXPERIMENT 1: PLANT RESPONSE TO DAMINOZIDE AND GA GNDER $_{3}$ PHOTOSELECTIVE COVERS WITH VARIOUS $\phi_{\mathrm{e}}$. After a 1 -week establishment period, 24 plants were placed in each of the five chamber having various $\phi_{\mathrm{e}}$. Six plants each received a spray of one of the following treatments to run off on the day of transfer to the chambers and, again, 2 weeks later: 1) $\mathrm{GA}_{3}$ at $50 \mathrm{mg} \cdot \mathrm{L}^{-1}$ (Pro-Gibb Plus, Abbott Laboratories, Chicago, Ill.), 2) daminozide at $3500 \mathrm{mg} \cdot \mathrm{L}^{-1}$ (Uniroyal Chem. Co), 3) daminozide at 3500 $\mathrm{mg} \cdot \mathrm{L}^{-1}+\mathrm{GA}_{3}$ at $50 \mathrm{mg} \cdot \mathrm{L}^{-1}$, and 4 ) water only (control). Daminozide is a late stage gibberellin $(\mathrm{GA})$ biosynthesis inhibitor that blocks the 3B-hydroxylation of $\mathrm{GA}_{20}$ to $\mathrm{GA}_{1}$ (Brown et al., 1997). Therefore, the combination of daminozide and $\mathrm{GA}_{3}$ was used to

Table 1. Transmission of photosynthetic photon flux (PPF), R:FR ratios, and estimated phytochrome photoequilibrium $\left(\phi_{\mathrm{e}}\right)$ of the photoselective covers.

\begin{tabular}{|c|c|c|c|}
\hline Treatment ${ }^{2}$ & $\begin{array}{c}\text { PPF } \\
\left(\mu \mathrm{mol} \cdot \mathrm{m}^{-2} \cdot \mathrm{s}^{-1}\right)\end{array}$ & $\phi_{e}^{\mathrm{y}}$ & $\mathrm{R}: \mathrm{FR}^{\mathrm{x}}$ \\
\hline Control & 1252 & 0.72 & 1.1 \\
\hline YBM-1 no. 85 & 1090 & 0.75 & 1.6 \\
\hline YBM-1 no. 75 & 980 & 0.78 & 2.7 \\
\hline YBM-1 no. 65 & 832 & 0.81 & 4.3 \\
\hline YBM-1 no. 55 & 748 & 0.83 & 6.1 \\
\hline
\end{tabular}

${ }^{\mathrm{z}}$ Number following YBM-1 indicates the percentage transmission of PPF.

${ }^{\mathrm{y}}$ Estimated as described by Sagar et al. (1988).

${ }^{\mathrm{x}} \mathrm{R}=600$ to $700 \mathrm{~nm} ; \mathrm{FR}=700$ to $800 \mathrm{~nm}$. 


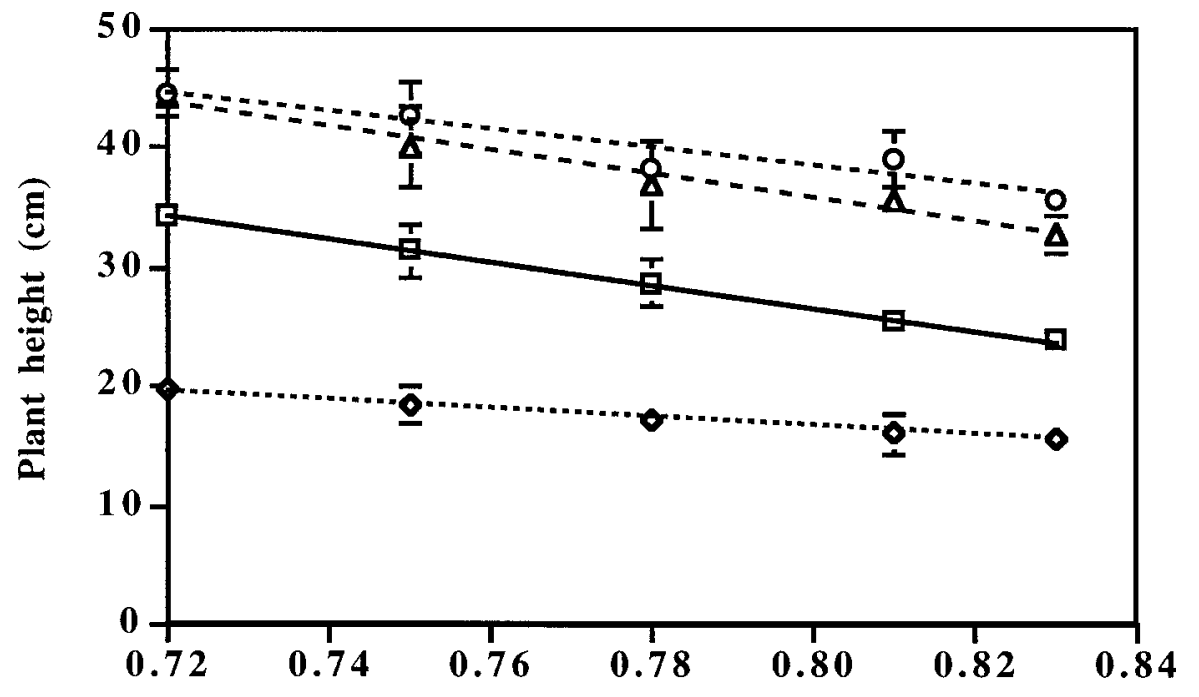

Phytochrome photoequilibrium $\left(\phi_{\mathbf{e}}\right)$

\begin{tabular}{|cccl|}
\hline$\square$ & Water & $\bullet$ & Daminozide \\
0 & $\mathbf{G A}_{3}$ & $\Delta$ & Daminozide $+\mathbf{G A}_{3}$ \\
\hline
\end{tabular}

spray (BAS 125 10W, BASF Corp., Research Triangle Park, N.C.), 4) combination of paclobutrazol at $0.73 \mathrm{mg}$ a.i. and prohexadione-Ca at $200 \mathrm{mg} \cdot \mathrm{L}^{-1}$ a.i (PA + $\mathrm{PR})$, 5) combination of paclobutrazol at $0.73 \mathrm{mg}$ a.i. and $\mathrm{GA}_{1}$ at $50 \mu \mathrm{g}\left(\mathrm{PA}+\mathrm{GA}_{1}\right)$, 6) combination of prohexadione-Ca at 200 $\mathrm{mg} \cdot \mathrm{L}^{-1}$ a.i. and $\mathrm{GA}_{1}$ at $\left.50 \mu \mathrm{g}\left(\mathrm{PR}+\mathrm{GA}_{1}\right), 7\right)$ combination of paclobutrazol at $0.73 \mathrm{mg}$ a.i., prohexadione-Ca at $200 \mathrm{mg} \cdot \mathrm{L}^{-1}$ a.i., and $\mathrm{GA}_{1}$ at $50 \mu \mathrm{g}\left(\mathrm{PA}+\mathrm{PR}+\mathrm{GA}_{1}\right)$, and 8$)$ water only (control). Plants were treated on the day of transfer to the growth chambers and, again, after 2 weeks in the chambers. $\mathrm{GA}_{1}$ was dissolved in $95 \%$ ethanol, diluted with water to $50 \%$ ethanol and was applied as a $10-\mu \mathrm{L}$ drop to the apex using a syringe. For the combination treatments, plants were pretreated with the respective growth retardant as described before $\mathrm{GA}_{1}$ application. A separate set of six control plants was treated with $50 \%$ ethanol and the height of controls did not differ. Plants in experimental chambers received an average daily PPF integral of $14.1 \pm 0.5 \mathrm{~mol} \cdot \mathrm{m}^{-2}$ on a clear day.

EXPERIMENTAL DESIGN AND ANALYSIS. EXperimental chambers were randomly posi-

Fig. 2. Effect of daminozide and $\mathrm{GA}_{3}$ on plant height of 'Bright Golden Anne' chrysanthemums grown under photoselective greenhouse covers with various phytochrome photoequilibrium estimates $\left(\phi_{\mathrm{e}}\right)$. Vertical bars indicate $\pm \mathrm{SE}(\mathrm{n}=$ 12). If the vertical bars are not seen, SE was smaller than the symbol. Lines were fitted to $y=\beta_{0}+\beta_{1} x$, where $y$ is height and $x$ is $\left(\phi_{e}-0.72\right)$. Intercept $\left(\beta_{0}\right)$ represents plant ht. inside the control chamber $\left(\phi_{\mathrm{e}}\right.$ of 0.72$)$. Predicted regression equations are: water, height $=34.3^{\mathrm{b}}-96.1^{\mathrm{A}} \mathrm{x}, r^{2}=0.99$; daminozide, height $=$ $19.5^{\mathrm{c}}-36.8^{\mathrm{B}} \mathrm{x}, r^{2}=0.99 ; \mathrm{GA}_{3}$, height $=44.5^{\mathrm{a}}-76.6^{\mathrm{A}} \mathrm{x}, r^{2}=0.90 ;$ daminozide + $\mathrm{GA}_{3}$, height $=43.6^{\mathrm{a}}-97.4^{\mathrm{A}} \mathrm{X}, r^{2}=0.97$. Intercepts $\left(\beta_{0}\right)$ and slopes $\left(\beta_{1}\right)$ with same superscripted letter (lowercase and uppercase, respectively) are not significantly different at $P=0.05$.

determine the responsiveness to $\mathrm{GA}_{3}$ when endogenous $\mathrm{GA}$ supply was blocked.

Plants were fertilized three times a week at irrigation with 1 $\mathrm{g} \cdot \mathrm{L}^{-1}$ of a $20 \mathrm{~N}-4.4 \mathrm{P}-16.7 \mathrm{~K}$ water soluble fertilizer (Peters 20 10-20 Peat-Lite Special, Scotts-Sierra Horticultural Products Co., Marysville, Ohio). Plants in all chambers received an average daily PPF integral of $15.5 \pm 0.3 \mathrm{~mol} \cdot \mathrm{m}^{-2}$ on a clear day. Daily maximum and minimum air temperatures inside chambers were recorded during the experiment. Average daily maximum (30 \pm $\left.2^{\circ} \mathrm{C}\right)$ or minimum $\left(20 \pm 1^{\circ} \mathrm{C}\right)$ temperatures during the experimental period were not different among chambers.

EXPERIMENT 2: PLANT RESPONSE TO EARLY AND LATE GA INHIBITORS UNDER HIGH $\phi_{\mathrm{e}}$. Plant response to paclobutrazol [early inhibitor of GA biosynthesis, Coolbaugh and Hamilton, 1976)] and prohexadione-Ca [late inhibitor of GA biosynthesis (Brown et al., 1997)] was evaluated inside control $(\phi=0.72)$ and YBM1 no. $55(\phi=0.83)$ chambers. Chrysanthemums were grown as described previously. After a 1-week establishment period, 48 plants were transferred to each chamber. A set of six plants in each chamber was treated with one of the following eight treatments: 1) $\mathrm{GA}_{1}$ at $50 \mu \mathrm{g}$ per apex (Sigma Chem. Co., St. Louis, Mo.) as a $10 \mu \mathrm{L}$ drop to the apex, 2) paclobutrazol (PA) at $0.73 \mathrm{mg}$ active ingredient (a.i.) per pot as a 10-mL soil drench (Bonzi, Uniroyal Chem. Co), 3) prohexadione-Ca (PR) at $200 \mathrm{mg} \cdot \mathrm{L}^{-1}$ a.i. as foliar tioned inside a glass greenhouse. Because of the limited number of chambers, experiments were repeated once to replicate. The experimental design was a randomized complete block design with a split-plot arrangement of the treatments. The light treatment $\left(\phi_{\mathrm{e}}\right)$ was the main plot factor and the growth regulator treatments were the subplots. The blocking factor for the experiment was the replicate. Sets of six plants were the experimental units for the subplot factor and groups of growth regulator treatment (four for expt. 1 and eight for expt. 2) were the experimental units for the whole plot factor.

Plant height (distance from the medium surface to shoot apex) was measured for 4 weeks at weekly intervals. The number of fully expanded leaves was counted, and leaf and stem dry weights (DWs) were taken at termination. Average internode length was determined as height/number of leaves. For DW measurements, shoots were oven-dried for $5 \mathrm{~d}$ at $85^{\circ} \mathrm{C}$.

Data from the experiment were analyzed using analysis of variance procedures of the PROC MIXED of SAS (SAS Inst., Inc., Cary, N.C.). The $\phi_{\mathrm{e}}$ factor was evaluated by linear, quadratic, cubic, and quadratic contrasts. Polynomial regression models were fit to the data using contrasts. Powers of $\left(\phi_{e}-0.72\right)$ were used so that the intercept term would represent the mean for the control light treatment value of $\phi_{e}(0.72)$. Comparisons of polynomial coefficients for the different growth regulator treatments were done using pairwise $t$ tests.

\section{Results}

Response to daminozide and Ga 3 UNDER PHotoselective COVERS WITH Various $\phi_{\mathrm{e}}$. Plant height decreased linearly $(P<$ $0.05)$ as the $\phi_{\mathrm{e}}$ increased, regardless of the growth regulator treatment (Fig. 2). The degree of height control by daminozide as $\phi_{\mathrm{e}}$ increased was less than that for water or $\mathrm{GA}_{3}$-treated plants. The rate of height decrease for the treatment with $\mathrm{GA}_{3}$ at increasing $\phi_{\mathrm{e}}$ was not significantly different from the water treated plants. 
Number of leaves was not affected by $\phi_{\mathrm{e}}$ or the growth regulator treatment (data not presented). Internode length responded to
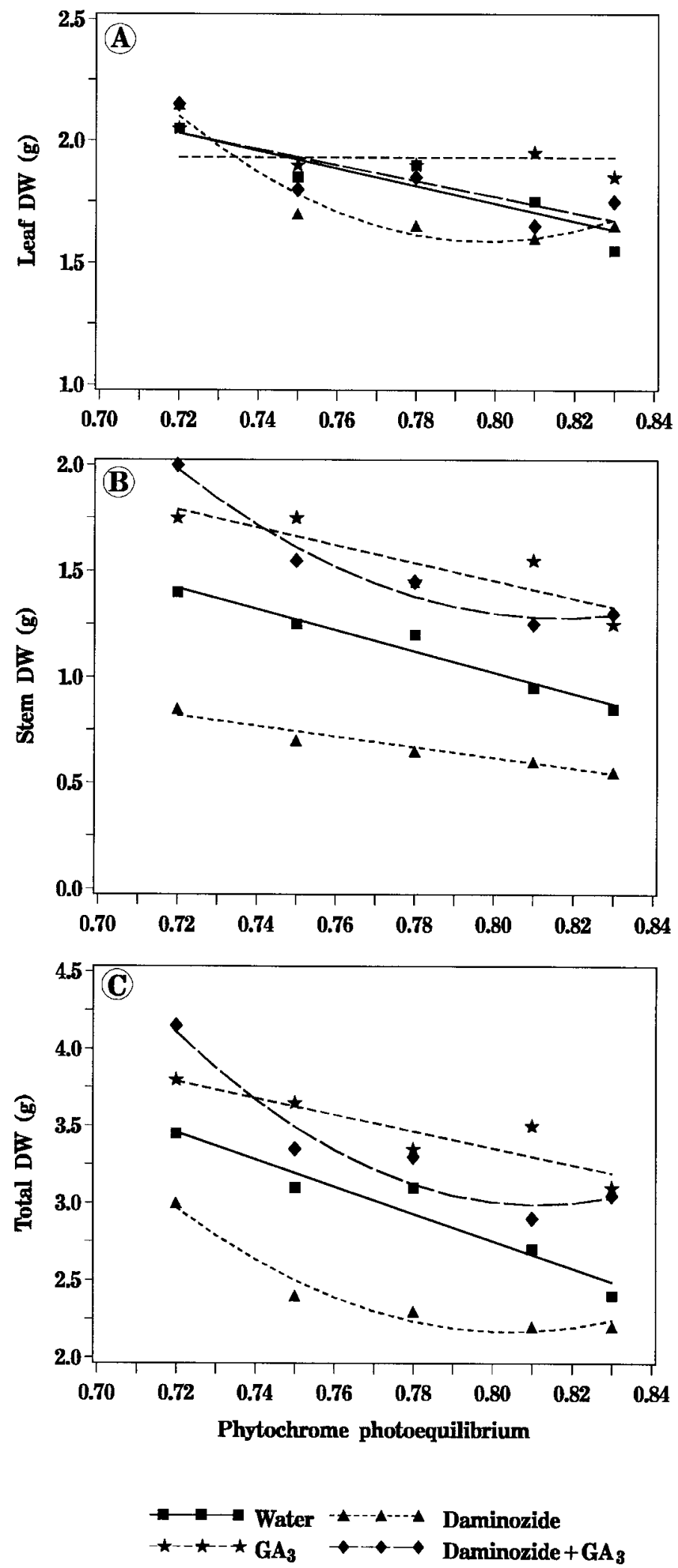

Fig. 3. Effect of daminozide and $\mathrm{GA}_{3}$ on (A) leaf, (B) stem, and (C) total dry weight of 'Bright Golden Anne' chrysanthemums grown under greenhouse covers with various phytochrome photoequilibrium estimats $\left(\phi_{\mathrm{e}}\right)$. increasing $\phi_{\mathrm{e}}$ in a similar pattern to that of height and growth regulator treatments (data not presented).

Dry matter accumulation was influenced by the photoselective covers and the growth regulator treatment (Fig. 3). Table 2 represents the regression coefficients of fitted lines in Fig. 3 and the significance of slopes at $P<0.05$. Leaf dry matter accumulation decreased as $\phi_{\mathrm{e}}$ increased, except for $\mathrm{GA}_{3}$-treated plants which had similar leaf DW at all $\phi_{\mathrm{e}}$. Leaf DW of water and daminozide $+\mathrm{GA}_{3}$-treated plants decreased linearly as the $\phi_{\mathrm{e}}$ increased while that of daminozide treatment followed a quadratic pattern. Stem DW of control (water) and daminozide treated plants decreased linearly as the $\phi_{\mathrm{e}}$ increased. The rate of decrease was greater in control plants (greater $\beta_{1}$, Table 2 ) than in daminozide treated plants. Total shoot DW of water and $\mathrm{GA}_{3}-$ treated plants decreased linearly while in daminozide treated plants it followed a quadratic trend. Overall, plants that received $\mathrm{GA}_{3}$ or daminozide $+\mathrm{GA}_{3}$ had greater DW. Specific stem DW (stem DW per unit length) or specific leaf DW (leaf DW per unit area) was not affected (data not presented), indicating that the decreased DW was mainly a result of smaller plants (data not presented).

EFFECTIVENESS OF EARLY AND LATE GA BIOSYNTHESIS INHIBITORS. Both paclobutrazol and prohexadione-Ca resulted in shorter plants in control $\left(\phi_{\mathrm{e}}=0.72\right)$ and YBM-1 no. $55\left(\phi_{\mathrm{e}}=0.83\right)$ chambers (Fig. 4), but the height reduction by paclobutrazol was more than that of prohexadione-Ca. The combination of paclobutrazol and prohexadione-Ca reduced plant height more than either of them alone. Exogenous $\mathrm{GA}_{1}$ increased plant height over the water-treated control in both light environments. $\mathrm{GA}_{1}$ treatment reversed height reduction caused by paclobutrazol and prohexadione-Ca in plants grown in control and YBM-1 chambers. The height increase by $\mathrm{GA}_{1}$ was greater when it was applied with prohexadione-Ca than when it was applied with paclobutrazol or alone. There was no significant interaction between the plant growth regulator and $\phi_{\mathrm{e}}$ treatments.

\section{Discussion}

Photoselective covers with high $\phi_{\mathrm{e}}$ reduced height of 'Bright Golden Anne' chrysanthemums without use of chemical growth retardants. In separate studies, the height of several vegetable and ornamental crops was also reduced by photoselective greenhouse covers, indicating that photoselective covers are effective for a wide range of crops (Rajapakse et al., 1999). The linear relationship between plant height and $\phi_{\mathrm{e}}$ (Fig. 2) in this study suggests that effectiveness of photoselective covers increases as $\phi_{\mathrm{e}}$ is increased. The PPF transmission of photoselective covers decreases as the $\phi_{\mathrm{e}}$ increases because of the increasing dye concentration. Identifying photoselective covers that effectively filter out FR light from sunlight and reduce plant height while minimizing the PPF reduction is critical for commercial success of photoselective covers. Our data indicate that photoselective covers with $\phi_{\mathrm{e}}$ of 0.78 (which corresponds to $\approx 25 \%$ PPF reduction) was effective in achieving a $20 \%$ to $30 \%$ height reduction of chrysanthemum(Oi et al., 1998; Rajapakse et al., 1998; Rajapakse et al., 1999).

Gibberellins are known to stimulate stem elongation of many plant species. The change in stem elongation in response to changes in R and FR light in the environment has been reported to be mediated by changes in gibberellin levels due to reduced synthesis (Morgan et al., 1980) or increased destruction (Lockhart, 1959), or by reduced responsiveness of plants to gibberellins 
Table 2. Regression coefficients of fitted lines for the relationship between leaf, stem or total DWs of 'Bright Golden Anne' chrysanthemums and phytochrome photoequilibrium estimates $\left(\phi_{\mathrm{e}}\right)$. Y $=\beta_{0}+\beta_{1}\left(\phi_{\mathrm{e}}-0.72\right)+\beta_{2}\left(\phi_{\mathrm{e}}-0.72\right)^{2}$.

\begin{tabular}{|c|c|c|c|}
\hline \multirow[b]{2}{*}{ Treatment } & \multicolumn{3}{|c|}{ Estimated regression coefficients } \\
\hline & $\beta_{0}$ & $\beta_{1}$ & $\beta_{2}$ \\
\hline & & Leaf & \\
\hline Water & $2.0 \mathrm{a}^{\mathrm{z}}$ & $-3.60 b$ & 0 \\
\hline Daminozide & $2.1 \mathrm{a}$ & $-13.2 \mathrm{a}$ & 85.3 \\
\hline $\mathrm{GA}_{3}$ & $1.9 \mathrm{a}$ & 0 & 0 \\
\hline \multirow[t]{2}{*}{ Daminozide $+\mathrm{GA}_{3}$} & $2.0 \mathrm{a}$ & $-3.3 b$ & 0 \\
\hline & & Stem & \\
\hline Water & $1.4 \mathrm{~b}$ & $-5.0 \mathrm{~b}$ & 0 \\
\hline Daminozide & $0.8 \mathrm{c}$ & $-2.5 \mathrm{c}$ & 0 \\
\hline $\mathrm{GA}_{3}$ & $1.8 \mathrm{a}$ & $-4.2 b$ & \\
\hline \multirow[t]{2}{*}{ Daminozide $+\mathrm{GA}_{3}$} & $2.0 \mathrm{a}$ & $-14.5 \mathrm{a}$ & 75.5 \\
\hline & & Total & \\
\hline Water & $3.5 \mathrm{bc}$ & $-8.8 \mathrm{~b}$ & 0 \\
\hline Daminozide & $3.0 \mathrm{c}$ & $-19.0 \mathrm{a}$ & $112.6 \mathrm{a}$ \\
\hline $\mathrm{GA}_{3}$ & $3.8 \mathrm{ab}$ & $-5.42 \mathrm{~b}$ & 0 \\
\hline Daminozide $+\mathrm{GA}_{3}$ & $4.1 \mathrm{a}$ & $-24.6 \mathrm{a}$ & $134.6 \mathrm{a}$ \\
\hline
\end{tabular}

${ }^{\mathrm{z}}$ Mean separation within columns for a tissue factor by pairwise $t$ test at $P=0.05$.

(Reid and Ross, 1988). It is possible, therefore, that photoselective covers reduce plant height by altering the gibberellin metabolism or the responsiveness. In the current experiments, both exogenous $\mathrm{GA}_{1}$ and $\mathrm{GA}_{3}$ reversed the height reduction caused by the photoselective covers with high $\phi_{\mathrm{e}}$. Our results with exogenous $\mathrm{GA}_{3}$ or $\mathrm{GA}_{1}$ application indicate that responsiveness to gibberellins was not reduced in plants grown under photoselective panels with high $\phi_{\mathrm{e}}$. It is possible that gibberellin levels may have been reduced in plants grown under high $\phi_{\mathrm{e}}$ environments. Our quantification studies (unpublished data) indicated that $\mathrm{GA}_{19}$ levels were higher and $\mathrm{GA}_{1}$ levels were lower in chrysanthemum plants grown under $\mathrm{CuSO} 4$ filters which had a $\phi_{\mathrm{e}}$ of 0.81 . In addition, metabolism of radiolabelled $\mathrm{GA}_{19}$ was slower in CuSO4-filter-grown plants than in control plants (unpublished data). These observations suggest that suppression of gibberellin biosynthesis may be the cause for reduced height under FR light depleted environments. Martinez-Garcia and GarciaMartinez (1992) reported that FR light-induced stem elongation of cowpea [Vigna sinensis (L.)] was related to increased levels of $\mathrm{GA}_{1}$. Campbell and Bonner (1986) reported that conversion of $\mathrm{GA}_{20}$ (inactive) to $\mathrm{GA}_{1}$ (active), occurs readily in dark-grown dwarf pea (Pisum sativum L.) seedlings and this conversion is prevented by $\mathrm{R}$ light.

Most chemical growth retardants, including the ones tested herein, reduce stem elongation by blocking gibberellin biosynthesis (Brown et al., 1997; Coolbaugh and Hamilton, 1976). If the mode of action of photoselective films were to block GA biosynthesis, plants treated with daminozide would not have responded under the high $\phi$ environment. In the present experiment, daminozide treatment further reduced the height of plants grown under photoselective covers indicating that the covers were not as effective as daminozide in blocking GA biosynthesis. The mag-

Fig. 4. Weekly height increase of 'Bright Golden Anne' chrysanthemums grown in (A) control or (B) YBM-1 no. 55 chambers in response to prohexadione-Ca (PR), paclobutrazole (PA), and $\mathrm{GA}_{1}$ application. Vertical bars indicate $\pm \mathrm{SE}(\mathrm{n}=$ 12). If the vertical bars are not seen, SE was smaller than the symbol.
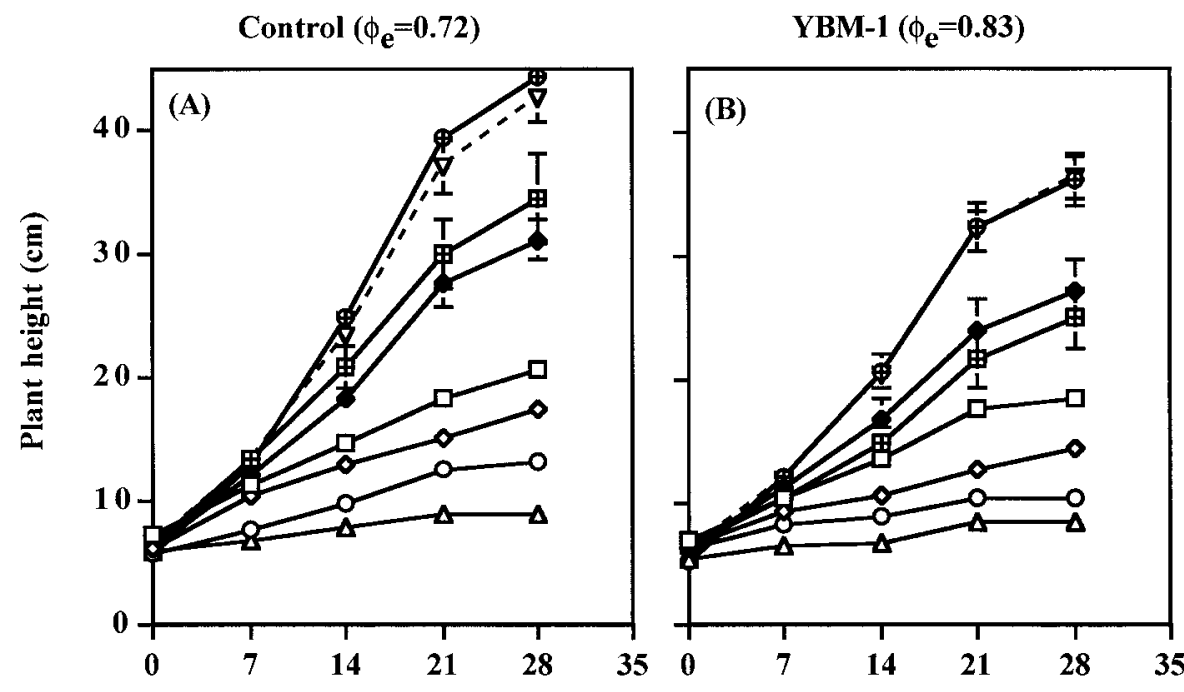

Days after treatment

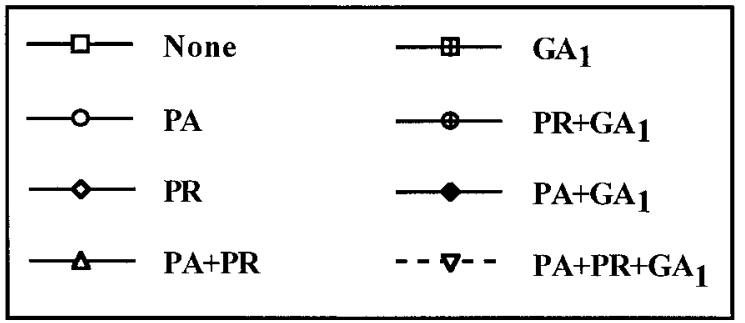


nitude of height reduction caused by daminozide decreased as $\phi_{\mathrm{e}}$ of the growing environment increased (Fig. 2), suggesting that GA biosynthesis may be progressively reduced as $\phi_{\mathrm{e}}$ increases.

Both paclobutrazol and prohexadione-Ca were effective in controlling plant height under a photoselective cover with high $\phi_{\mathrm{e}}$, but paclobutrazol was more effective than prohexadione-Ca in reducing stem elongation (Fig. 4). The difference in effectiveness between the two compounds could be due to different modes of action. Paclobutrazol blocks an early step in the gibberellin biosynthetic pathway [oxidation of ent-kaurene to $\mathrm{GA}_{12}$ (Coolbaugh and Hamilton, 1976)], whereas prohexadione-Ca blocks a late step in the pathway [3 $\beta$-hydroxylation of $\mathrm{GA}_{20}$ to $\mathrm{GA}_{1}$ (Brown et al., 1997)]. Prohexadione-Ca has been also shown to prevent metabolism of $\mathrm{GA}_{1}$ to inactive $\mathrm{GA}_{8}$ by blocking the $2 \beta$ hydroxylation (Brown et al., 1997).

Exogenous $\mathrm{GA}_{1}$ promoted growth of paclobutrazol or prohexadione-Ca-treated plants regardless of the light environment. This also shows that the shorter plants under the photoselective cover were not a result of reduced sensitivity to gibberellins. Maas and van Hattum (1998) reported that paclobutrazol-treated fuchsia (Fuchsia $\times$ hybrida Hort. ex Vilm.) plants showed a similar response to exogenous $\mathrm{GA}_{1}$ when grown at higher night temperatures than day temperatures (-DIF) or at higher day temperatures than night temperatures (+DIF). They also reported that response to $\mathrm{GA}_{1}$ was similar under white or orange light regardless of the temperature regime. Their data suggested that the differences in shoot elongation they observed under various light and temperature conditions did not result from light quality or day/night temperature mediated changes in plant sensitivity to $\mathrm{GA}_{1}$. Assuming that these growth retardants block GA biosynthesis, the additional height reduction by growth retardants under photoselective covers suggests that gibberellin biosynthesis may not be the only height controlling mechanism under photoselective covers.

When applied together with prohexadione-Ca, $\mathrm{GA}_{1}$ in the plant may be sustained for a longer period thereby increasing plant height greater than treatment with $\mathrm{GA}_{1}$ alone (Fig. 4). Recent work by Ait-Ali et al. (1999) has shown that exposure of etiolated pea seedlings to white light decreased $\mathrm{GA}_{1}$ levels due to increased $2 \beta$ hydroxylase activity. Their results show that light-enhanced degradation of $\mathrm{GA}_{1}$ plays a role in reduced stem elongation when dark grown plants are transferred to light. If photoselective covers enhance metabolism of $\mathrm{GA}_{1}$ to $\mathrm{GA}_{8}$, the response to exogenous $\mathrm{GA}_{1}$ and the combination of prohexadione-Ca and $\mathrm{GA}_{1}$ should have been small under photoselective covers. $\mathrm{GA}_{1}$ increased the height of plants grown under photoselective covers and when applied with prohexadione-Ca, height increase was greater than $\mathrm{GA}_{1}$ alone, indicating that the increased metabolism of $\mathrm{GA}_{1}$ to $\mathrm{GA}_{8}$ did not cause height reduction by photoselective covers.

In summary, our results show that photoselective greenhouse covers with high $\phi_{\mathrm{e}}$ controlled height of greenhouse-grown 'Bright Golden Anne' chrysanthemums without chemical growth retardants. Photoselective covers with $\phi_{\mathrm{e}}$ of 0.78 were effective in achieving $\approx 20 \%$ height reduction without chemical growth regulators. In the present work, experimental chambers were kept inside a glasshouse so that the PPF reduction was greater than if the photoselective covers were used as the primary cover. If the photoselective covers were used as the primary greenhouse cover, then the covers with higher $\phi_{\mathrm{e}}$ than 0.78 may still provide sufficient
PPF to grow a satisfactory crop, especially in southern latitudes where irradiance is high. Results also suggest that gibberellins are at least partially involved in height reduction induced by photoselective covers. Photoselective greenhouse covers did not reduce the responsiveness to gibberellins, and it appears that the mechanism may be to suppress gibberellin biosynthesis. Photoselective covers were not as effective as chemical growth retardants in suppressing gibberellin biosynthesis.

\section{Literature Cited}

Ait-Ali, T., S. Frances, J.L. Weller, J.B. Reid, R.E. Kendrick, and Y. Kamiya. 1999. Regulation of $\mathrm{GA}_{20}$-oxidase and GA $3 \beta$-hydroxylase transcript accumulation during phytochrome-mediated de-etiolation of pea seedlings. Plant Physiol. 121:783-791.

Brown, R.G.S, H. Kawaide, Y. Yang, W. Rademacher, and Y. Kamiya. 1997. Daminozide and prohexadione-Ca have similar modes of action as inhibitors of the late stages of gibberellin metabolism. Physiol. Plant. 101:309-313.

Campell, B.R. and B.A. Bonner. 1986. Evidence for phytochrome regulation of gibberellin $\mathrm{A}_{20} 3 \beta$-hydroxylation in shoots of dwarf (lele) Pisum sativum L. Plant Physiol. 82:909-915.

Coolbaugh, R.C. and R. Hamilton. 1976. Inhibition of ent-kaurene oxidation and growth by $\alpha$-cyclopropyl- $\alpha$-(p-methoxy-phenyl)-5-pyrimidine methyl alcohol. Plant Physiol. 57:245-248.

Hayward, P.M. 1984. Determination of phytochrome parameters from radiation measurements, p. 159-173. In: H. Smith and M.G. Holms (eds.). Techniques in photomorphogenesis. Academic Press, London. Lockhart, J.A. 1959. Studies on the mechanism of stem growth inhibition by visible radiation. Plant Physiol. 34:457-460.

Maas F.M. and J. van Hattum. 1998 Thermomorphogenic and photomorphogenic control of stem elongation in fuchsia is not mediated by changes in responsiveness to gibberellins J. Plant Growth Regul. 17:39-45.

Martinez-Garcia, J. and J.L. Garcia-Martinez. 1992. Phytochrome modulation of gibberellin metabolism in cowpea epicotyls, p. 585-590. In: C.M. Karssen, L.C. van Loon, and D. Vreugdenhil. (eds.). Progress in plant growth regulation. Kluwer Academic Publishers, Dordrecht, The Netherlands.

Morgan, D.C., T. O'Brien, and H. Smith. 1980. Rapid photomodulation of stem extension in light-grown Sinapis alba L. Studies on kinetics, site of perception and photoreceptor. Planta 150:95-101.

Morgan, D.C. and H. Smith. 1976. Linear relationship between phytochrome photoequilibrium and growth in plants under simulated natural radiation. Nature 262:210-212.

Morgan, D.C. and H. Smith. 1979. A systematic relationship between phytochrome-controlled development and species habitat, for plants grown in simulated natural radiation. Planta 145:253-258.

Oi, R., N. Arai, Y. Matsuzaki, K. Seino, O. Kohgo, S. Ikado, M. Iwata, and K. Murakami. 1998. Photoselective plastics and their effects on plant growth. Proc. Natl. Agr. Plastics Congr. 27:35-40.

Rajapakse, N.C. and J.W. Kelly. 1992. Regulation of chrysanthemum growth by spectral filters. J. Amer. Soc. Hort. Sci. 117:481-485.

Rajapakse, N.C., R.E. Young, M.J. McMahon, and R. Oi. 1999. Plant height control by photoselective filters: Current status and future prospects. HortTechnology 9:618-624.

Rajapakse, N.C., R.E. Young, and R. Oi. 1998. Plant growth regulation by photoselective greenhouse covers. Proc. Natl. Agric. Plastics Congress 27:23-29.

Reid, J.B. and J.J. Ross. 1988. Internode length in Pisum. A new gene, lv, conferring an enhanced response to gibberellin A1. Physiol. Plant. 72:595-604.

Sager, J.C., W.O. Smith, J.C. Edwards, and K.L. Cyr. 1988. Photosynthetic efficiency and phytochrome equilibria determination using spectral data. Trans. Amer. Soc. Agr. Eng. 31:1882-1887. 